\title{
Cervical Thymic Cyst Presenting as a Solitary Cervical Cystic Mass in a 57-Year-Old Woman : A Case Report and Literature Review
}

\author{
Taek Yoon Cheong, $\mathrm{MD}^{1}$, Mee Joo, $\mathrm{MD}, \mathrm{PhD}^{2}$, and Yoon Kyoung So, $\mathrm{MD}, \mathrm{PhD}^{1}$ \\ ${ }^{1}$ Department of Otorhinolaryngology-Head and Neck Surgery, Ilsan Paik Hospital; ${ }^{2}$ Pathology, Ilsan Paik Hospital, \\ Inje University College of Medicine, Goyang, Korea
}

\begin{abstract}
- ABSTRACT -
Cervical thymic cyst (CTC) is a rare congenital disease that can appear during the developmental course of the thymus. CTCs rarely present in adulthood and can be difficult to diagnose. We present a case of CTC mimicking a cystic lymph node in an adult patient. A 57-year-old female presented a with a left left-sided painless neck mass, which was found in two weeks before prior. Computed tomography (CT) finding showed a 2-cm-sized cystic mass with wall enhancement in contact with the left common carotid artery. Fine-needle aspiration cytology was non-diagnostic. Surgical exploration revealed a cystic mass surrounded by fatty tissue. CTC within the ectopic thymus was diagnosed postoperatively with demonstration of Hassall's corpuscle and the cystic wall lined by ciliated columnar or squamous cells. CTCs are extremely rare in adults. They are difficult to be diagnosed preoperatively. Because CTCs can present as a solitary cystic mass mimicking a solitary cystic lymph node, they should be ruled out in the diagnostic course. As known previously, the treatment is the complete excision of the cyst along with surrounding ectopic thymic tissue. (J Clinical Otolaryngol 2020;31:271-275)
\end{abstract}

KEY WORDS: Cervical thymic cyst $\cdot$ Ectopic thymus $\cdot$ Cervical cyst $\cdot$ Thymus $\cdot$ Adult.

\section{Introduction}

Cervical thymic cyst (CTC) is a rare congenital disease, accounting for less than $1 \%$ of all cervical masses. ${ }^{1,2)}$ It can appear anywhere in the neck during the developmental course of the thymus. ${ }^{2}$ The primary pathognomonic findings are thymic parenchyma, lymphoid tissue, and Hassal's corpuscles in the cystic wall. ${ }^{3}$ They present most frequently as painless masses without accompanying symptoms. CTCs remain frequently undiagnosed, as suggested by autopsy studies reporting the prevalence of CTCs to be $9 \%{ }^{4)}$ Also, CTCs are frequently misdiagnosed preoperatively as other diseases. Because most cases present in childhood, they are more difficult to be diagnosed in adults. Especially, identification of CTCs presenting as small solitary cervical cysts in adults is a diagnostic challenge because they mimic cystic lymph node metastasis of unknown origin. Here, we present a case of CTC mimicking a cystic lymph node in an adult patient. This report was approved by the Ethics committee of Ilsan Paik Hospital, Inje University College of Medicine.

\section{Case Report}

A 57-year-old female patient presented with a twoweek history of a left-side, painless neck mass. The patient had no symptoms of upper respiratory infec-

논문접수일: 2020년 7월 15일 / 논문수정일: 2020년 8월 31일 / 심사완료일: 2020년 9월 18일

교신저자: 소윤경, 10380 경기도 고양시 일산서구 주화로 170 , 인제대학교 의과대학 일산백병원 이비인후과

전화: (031) 910-7250 ·전송: (031) 910-7747·E-mail: hn0131@paik.ac.kr 
tion, and the size of the mass had not changed since detection. Physical examination revealed a 2-cm-sized, rubbery, hard, slightly tender mass in the left side of the neck. No other significant findings were found during routine ear, nose, and throat examination, including an endoscopic examination of oropharynx, larynx, hypopharynx, and nasopharynx. When the patient was followed up after taking nonsteroidal anti-inflammatory medication (ibuprofen 1,200 mg per day) for one week, the size of the mass had not changed. Neck computed tomography (CT) was conducted, and sonography-guided fine-needle aspiration (FNA) was performed for the mass. The neck CT scan visualized a 2-cm-sized cystic mass with wall enhancement in the left side of the neck, medial to the anterior border of the sternocleidomastoid muscle, and in contact with the common carotid artery (Fig. 1). Ultrasonography-guided FNA yielded some
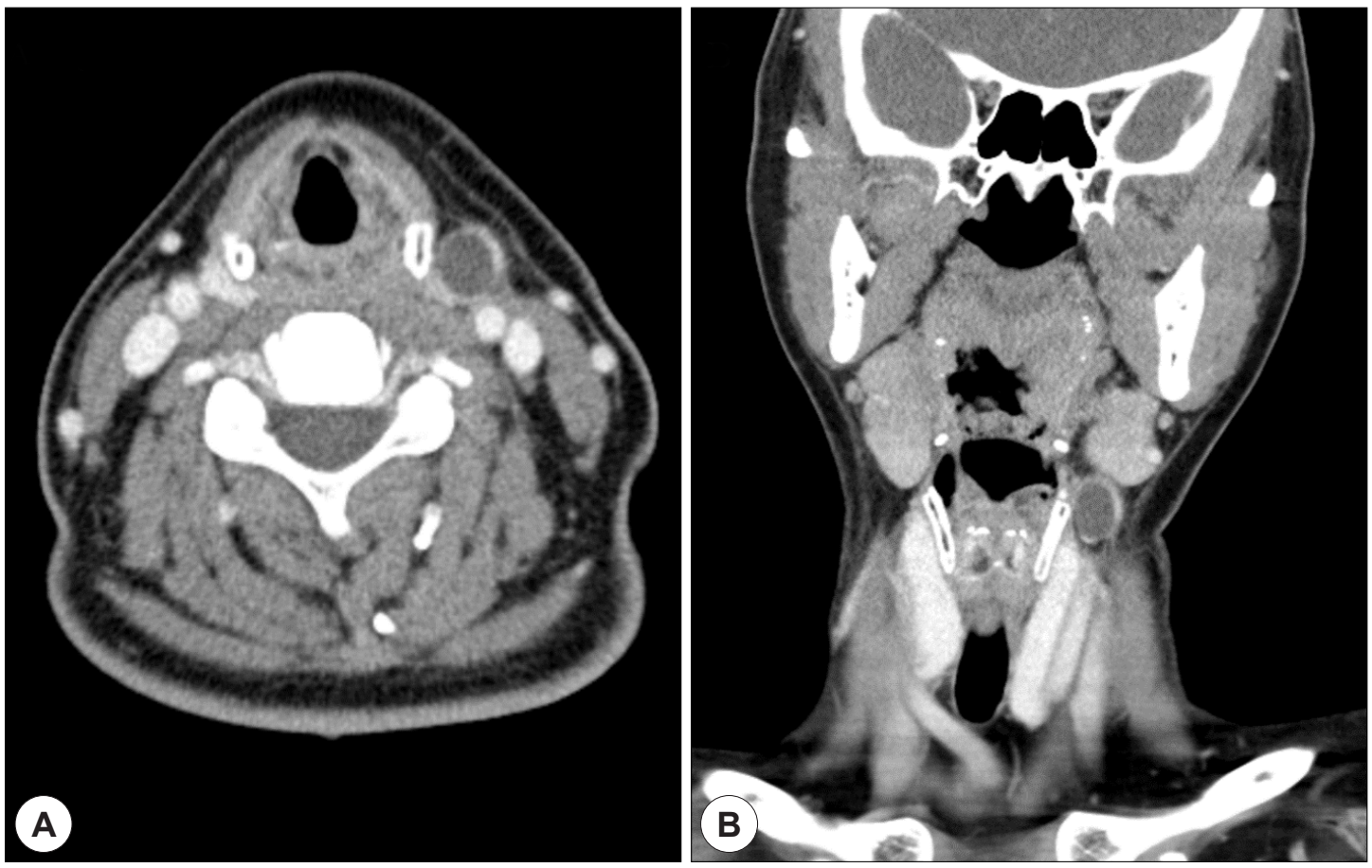

Fig. 1. CT scan. Axial (A) and a coronal (B) images with contrast enhancement show a cystic mass with wall enhancement medial to the anterior border of the sternocleidomastoid muscle, in contact with the common carotid artery in the left side of the neck. scattered inflammatory cells, which were not diagnostic. The result of polymerase chain reaction testing for tuberculosis infection (TB-PCR) of the FNA specimen was negative. Therefore, we performed surgical excision of the mass for both diagnostic and therapeutic purposes. Surgical exploration revealed unusual lipoma-looking fatty tissue in level II area. A cystic mass, apparent on the CT scan, was located within the fatty tissue (Fig. 2). The fatty tissue and the mass were contact with the common carotid artery. Pathologic examination demonstrated a unilocular cystic lesion with an inflamed fibrous wall. Thymic tissues with Hassall's corpuscles were identified within the fat tissue and the fibrous wall (Fig. 3). CTC within the ectopic thymus was diagnosed pathologically. The postoperative course was uneventful without any complications. With follow-up for 3 months, no recurrence was found clinically. 

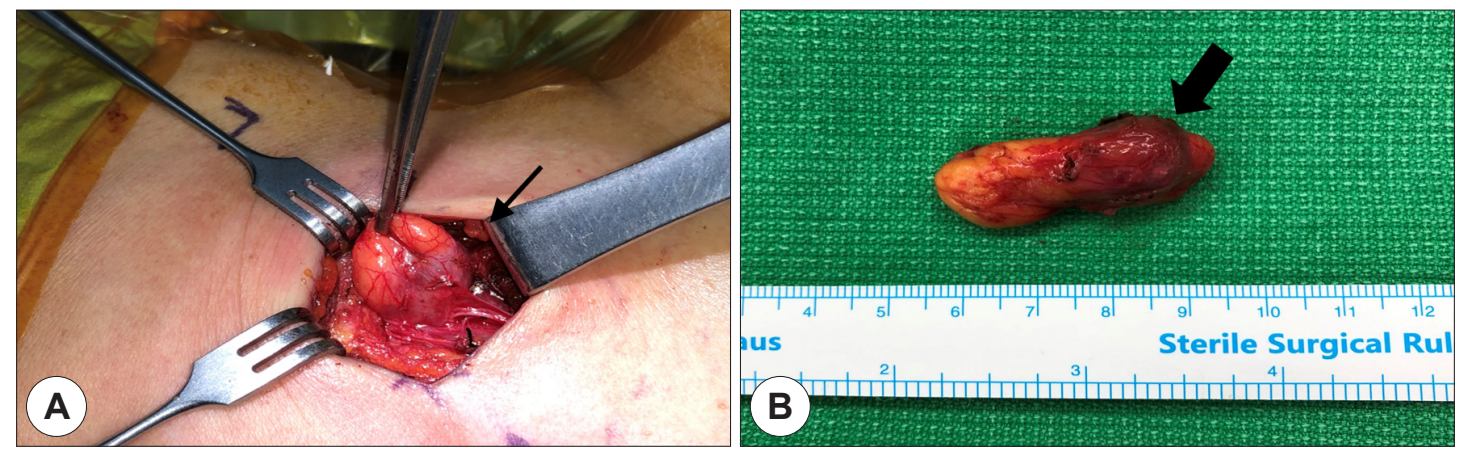

Fig. 2. Gross findngs of the mass. (A) Surgical exploration revealed unusual lipoma-looking fatty tissue (arrow) in level Il area. (B) A cystic mass (arrow) was apparent within the fatty tissue.
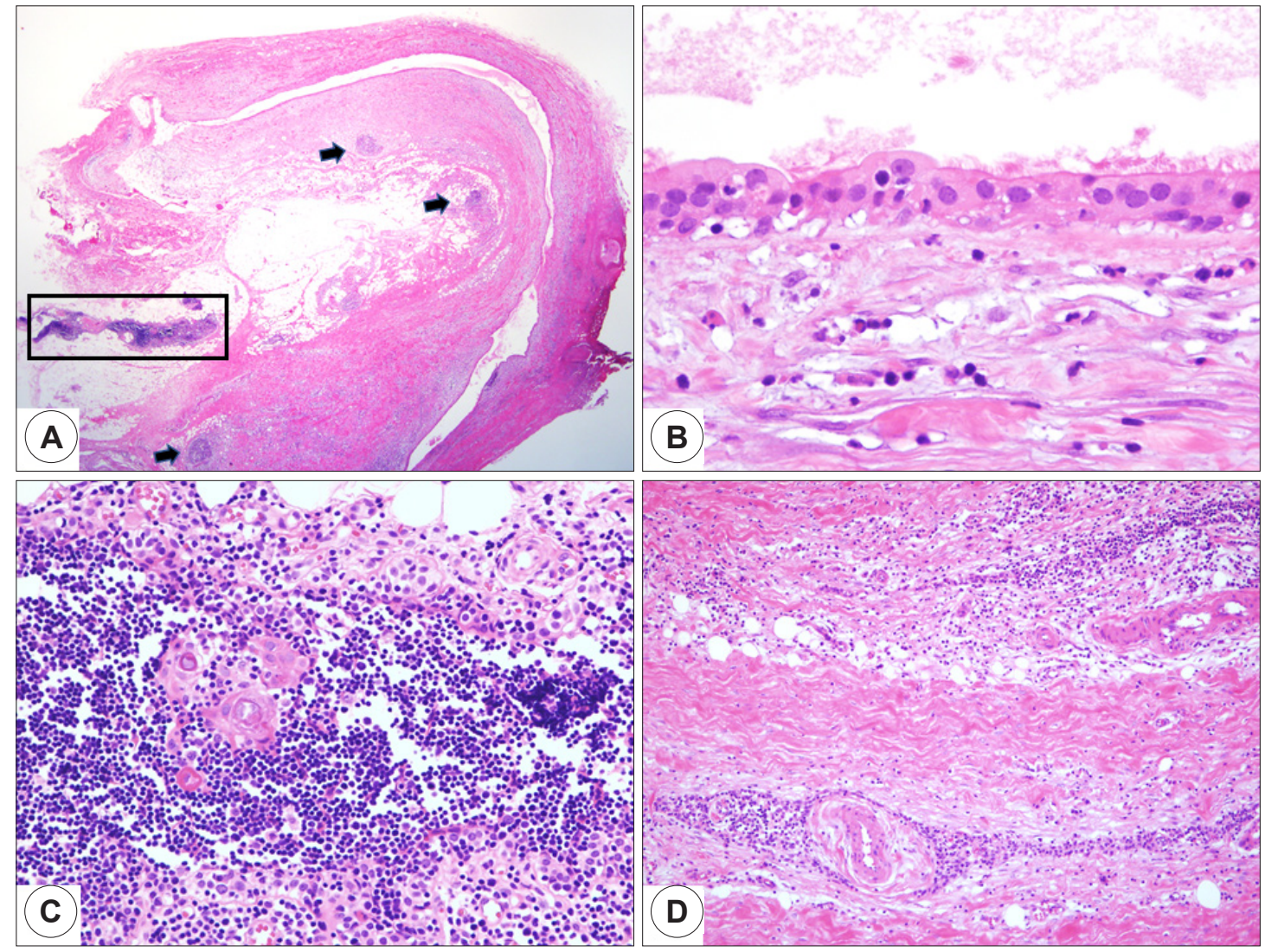

Fig. 3. Pathologic findings. (A) A low-magnification microphotograph shows a unilocular cystic lesion with an inflamed fibrous wall. Thymic tissues were identified within the fat tissue (black open square) and the fibrous wall (black arrows). (B) The lining cells are ciliated columnar or squamous cells [hematoxylin and eosin (H\&E), $\times 400$ ]. (C) High-magnification view indicated by the open black square in A reveals thymic tissue with Hassall's corpuscles (H\&E, $\times 200)(D)$ Atrophic elements of thymic tissue are multifocally seen in the cystic wall $(H \& E, \times 100)$. 


\section{Discussion}

Ectopic thymus and CTC can appear during the development of the thymus. The thymus is derived from the thymopharyngeal duct in the third and fourth pharyngeal pouches. The thymopharyngeal duct migrates from the pyriform sinus to the mediastinum until the ninth week of gestation, with bilateral ducts merging at the midline. ${ }^{2)}$ By the third month of gestation, the thymus matures to have a cortex and a medulla, and Hassall's corpuscles become apparent. ${ }^{5)}$ The superior portion of the thymopharyngeal duct regresses in its developmental course, but failure to do so may lead to unilocular cervical thymic cyst formation. Therefore, CTCs can develop in the neck anywhere between the angle of the mandible to the manubrium of the sternum. Also, cystic degeneration of Hassall's corpuscles within ectopic thymus remnants could become the origin of acquired multilocular thymic cyst. ${ }^{6}$

The thymus reaches its largest size between the ages of two and four years, ${ }^{7}$ and most CTCs present clinically between the ages of two and 13 years. ${ }^{8)}$ The majority of CTCs have been reported to develop in the left side and there was a slight male predominance. ${ }^{9)}$ CTCs are extremely rare in adults, with just 36 cases reported in a systematic review in 2011. In addition, they are more difficult to clarify via differential diagnosis in adults. Generally, differential diagnosis for lateral cystic neck masses includes common branchial cleft cyst, cystic hygroma, cystic teratoma, lipoma, cystic lymphadenopathy/lymphoma. ${ }^{3)}$ Metastatic lymph nodes with cystic changes should also be considered carefully as a differential diagnosis, especially in adults. ${ }^{10,11)}$ When considering their rarity and various differential diagnoses including metastatic LNs, CTC management is a diagnostic challenge in adults.

Radiologic tests such as CT and sonography can help in localization and characterization of such a mass. However, the findings of these radiologic tests are nonspecific and inconclusive. When diagnosing a solitary cervical mass, CT can reveal the nature, size, and location of the mass. Especially with regard to CTCs, information such as location relative to the carotid space and mediastinal extension can be obtained via CT. However, those findings are not specifically indicative of CTCs. Mediastinal extension may be observable in about half of adult patients with CTCs. ${ }^{9}$ In our case, the mass was in close contact with the common carotid artery, without any connection with the mediastinal thymus. High-resolution ultrasound has been reported to demonstrate characteristic multiple linear structures and echogenic foci. ${ }^{12)}$ However, in this case, these findings were absent. The cyst fluid may be clear, straw-colored, red, brown, gelatinous, or even purulent. Further, it may be semisolid due to necrotic debris, blood, and cholesterol crystals. ${ }^{3,7)}$ The cytology of the cystic fluid usually cannot offer any diagnostic information; for example, in this report, aspiration cytology of the mass yielded only some scattered inflammatory cells.

To date, the only diagnostic method for CTCs is surgical pathology, and most cases are diagnosed postoperatively. FNA specimen may only contain proteinaceous or mucinous debris consistent with cystic contents and be non-diagnostic. Core needle biopsy specimen may also include the surrounding fibrous tissue and adjacent thymic tissue, which can help the preoperative diagnosis in some cases. ${ }^{13)}$ Identification of thymic tissue with Hassall's corpuscles is necessary for the diagnosis. ${ }^{2,3)}$ The cyst wall may be lined with squamous, cuboidal, or ciliated columnar epithelium. ${ }^{9}$ Careful surgical exploration is the appropriate diagnostic procedure for neck CTCs and other neck masses, especially when FNA cytology does not yield a diagnostic finding. Complete surgical excision is also a treatment of choice. There have been no reported instances of recurrence following complete excision of CTCs in pediatric and adult patients. ${ }^{9}$ 


\section{Conclusions}

This case suggests that CTC can present as a small cervical cystic mass mimicking a cystic metastatic lymph node. It is difficult to diagnose before surgery, so it is necessary to completely remove it and check the biopsy after surgery. Because CTCs are extremely rare in adults, the cases are worth reporting and consideration.

\section{REFERENCES}

1) Lyons TJ, Dickson JA, Variend S. Cervical thymic cysts. J Pediatr Surg 1989;24(3):241-3.

2) Sturm-O'Brien AK, Salazar JD, Byrd RH, Popek EJ, Giannoni CM, Friedman EM, et al. Cervical thymic anomalies--the Texas Children's Hospital experience. Laryngoscope 2009;119(10):1988-93.

3) Millman B, Pransky S, Castillo J, 3rd, Zipfel TE, Wood WE. Cervical thymic anomalies. Int J Pediatr Otorhinolaryngol 1999;47(1):29-39.

4) Pages A, Girardot B. Cervical thymic choristoma. Ann Pathol 1993;13(3):164-9.
5) Statham MM, Mehta D, Willging JP. Cervical thymic remnants in children. Int J Pediatr Otorhinolaryngol 2008;72(12):1807-13.

6) Saggese D, Ceroni Compadretti G, Cartaroni C. Cervical ectopic thymus: a case report and review of the literature. Int J Pediatr Otorhinolaryngol 2002;66(1):77-80.

7) Kelley DJ, Gerber ME, Willging JP. Cervicomediastinal thymic cysts. Int J Pediatr Otorhinolaryngol 1997;39(2):139-46.

8) Cigliano B, Baltogiannis N, De Marco M, Faviou E, Antoniou D, De Luca U, et al. Cervical thymic cysts. Pediatr Surg Int 2007;23(12):1219-25.

9) Michalopoulos N, Papavramidis TS, Karayannopoulou G, Cheva A, Pliakos I, Triantafilopoulou K, et al. Cervical thymic cysts in adults. Thyroid 2011;21(9):987-92.

10) Goldenberg D, Sciubba J, Koch WM. Cystic metastasis from head and neck squamous cell cancer: a distinct disease variant? Head Neck 2006;28(7):633-8.

11) Rosenberg TL, Brown JJ, Jefferson GD. Evaluating the adult patient with a neck mass. Med Clin North Am 2010;94(5):1017-29.

12) Han BK, Yoon HK, Suh YL. Thymic ultrasound. II. Diagnosis of aberrant cervical thymus. Pediatr Radiol 2001;31(7):480-7.

13) Illei PB, Shyu S. Fine needle aspiration of thymic epithelial neoplasms and non-neoplastic lesions. Semin Diagn Pathol 2020;37(4):166-73. 